\title{
Estimating Winter Wheat Leaf Area Index From Ground and Hyperspectral Observations Using Vegetation Indices
}

\author{
Qiaoyun Xie, Wenjiang Huang, Bing Zhang, Senior Member, IEEE, Pengfei Chen, Xiaoyu Song, \\ Simone Pascucci, Stefano Pignatti, Giovanni Laneve, Member, IEEE, and Yingying Dong
}

\begin{abstract}
Growing numbers of studies have focused on evaluating the ability of vegetation indices (VIs) to predict biophysical parameters such as leaf area index (LAI) and chlorophyll. In this study, empirical models were used to estimate winter wheat LAI based on three spectral indices [the normalized difference vegetation index (NDVI), the modified simple ratio index (MSR), and the modified soil-adjusted vegetation index (MSAVI)], and three band-selection approaches (the conventional approach, the red edge approach, and the best correlated approach), which were used to calculate VIs. The aim was to enhance the relationships between the indices and LAI values by improving the band-selection approaches so as to produce a suitable VI for winter wheat LAI estimation. Using hyperspectral airborne data and ground-measured spectra as well as ground LAI measurements collected during two field campaigns, winter wheat LAIs were estimated and validated using different VIs calculated by different band combinations. Our results showed that the MSAVI provided the best LAI estimations when using ground measured spectra with $R^{2}$ over 0.74 and RMSE less than 0.98 . The NDVI provided the most robust estimation results across different sites, years, and sensors, although it was not adequate for LAI estimation of moderately dense canopies due to the saturation that occurred when LAI $>3$. The MSR demonstrated more severe scattering
\end{abstract}

Manuscript received March 10, 2015; revised September 25, 2015; accepted October 06, 2015. This work was supported in part by the National Natural Science Foundation of China under Grant 41325004, in part by the Special Fund from Chinese Academy of Sciences under Grant KZZD-EW-TZ-18, and in part by Sino-Italian Project "Development of analysis and assimilation techniques of new advanced earth observation satellite data into crop models: the case study of cereal crops in Italy and China."

Q. Xie is with the Key Laboratory of Digital Earth Science, Institute of Remote Sensing and Digital Earth, Chinese Academy of Sciences, Beijing 100094, China, and also with the University of Chinese Academy of Sciences, Beijing 100049, China (e-mail: xieqiaoyun2011@gmail.com).

W. Huang, B. Zhang, and Y. Dong are with the Key Laboratory of Digital Earth Science, Institute of Remote Sensing and Digital Earth, Chinese Academy of Sciences, Beijing 100094, China (e-mail: huangwen jiang@gmail.com; zb@ radi.ac.cn; cici5201@163.com).

P. Chen is with the State Key Laboratory of Resources and Environment Information System, Institute of Geographic Science and Natural Resources, Research of Chinese Academy of Sciences, Beijing 100101, China (e-mail: pengfeichen@igsnrr.ac.cn).

$\mathrm{X}$. Song is with Beijing Research Center for Information Technology in Agriculture, Beijing 100097, China (e-mail: songxy@nercita.org.cn).

S. Pascucci and S. Pignatti are with the Institute of Methodologies for Environmental Analysis, National Research Council of Italy, Rome 00133, Italy (e-mail: simone.pascucci@cnr.it; simone.pascucci@cnr.it).

G. Laneve is with the Department of Astronautics, Electrics, and Energetic, Sapienza University of Rome, Rome 00138, Italy (e-mail: giovanni. laneve@uniroma1.it).

Color versions of one or more of the figures in this paper are available online at http://ieeexplore.ieee.org.

Digital Object Identifier 10.1109/JSTARS.2015.2489718 and lower predictive accuracy than the NDVI and, therefore, was not a perfect solution to the saturation issue. In addition, it was also shown that the best correlated approach improved the predictive power of the indices and revealed the importance of red edge bands for LAI estimation; meanwhile, the red edge approach (based on the reflectance at 705 and $750 \mathrm{~nm}$ ) was not always superior to the conventional approach (based on the reflectance at 670 and $800 \mathrm{~nm}$ ). The results were promising and should facilitate the use of VIs in crop LAI measurements.

Index Terms-Hyperspectral, leaf area index (LAI), precision agriculture, spectral indices, winter wheat.

\section{INTRODUCTION}

$\mathbf{T}$ HE LEAF area index (LAI) is a major canopy biophysical parameter that can be used in the study of physiological processes in vegetation and ecosystem functioning [1]. Assessment of crop LAI and its spatial distribution in agricultural landscapes is important such as in crop growth monitoring, crop yield estimation, crop disease monitoring and forecasting, vegetation stress monitoring, and also in deciding on suitable management practices [2]. The analysis of ground imaging spectrometry allows the identification of spectrum features which can provide a quantitative estimate of biochemical and biophysical variables related to the physiological state of the crop vegetation [3], whereas airborne/satellite hyperspectral remote sensing provides a quick and large-scale approach to the estimation of crop LAI and this has led to the development of various methodologies for LAI estimation at diverse scales and for different types of vegetation canopies [4]. Generally, there are two common types of remote sensing methods that can be used for LAI estimation. The first type is the statistical method, which draws on a regression analysis expression obtained from the relationship between the spectral reflectance at the crop canopy level and the ground-measured LAI [5]-[7]. The other type uses an inverted radiative transfer model that includes the spectral reflectance at the crop canopy level [8], [9]. Due in part to their simplicity and transparency, vegetation indices (VIs) are among the most widely used satellite products, providing key measurements of LAI for studies of productivity, phenology, biochemistry, climate, and hydrology [10]-[13]. Hyperspectral indices evaluation can both reduce the data dimensionality and help understanding and evaluating the vegetation status (i.e., health or stress status) [14]. The combination of suitable indices allows the removal of redundant bands by the selection of 
optimal bands that capture only the optical plant/vegetation characteristics [15]. Therefore, the retrieval of suitable spectral VIs implies a rigorous study and also a statistical approach used both for estimating vegetation biophysical characteristics by remotely sensed data. Otherwise, a physical approach involving radiative transfer models describing the variation of canopy reflectance as a function of canopy, leaf, and background characteristics is commonly used [16]. For this study, regression expression based on VIs was applied for LAI monitoring in a selected test site, since it was more consolidated and was then more appropriate for testing the hyperspectral imaging platform. The indices investigated in this study include the normalized difference vegetation index (NDVI) [17], the modified simple ratio index (MSR) [18], and the modified soil-adjusted vegetation index (MSAVI) [19]. Although these indices are closely related to the LAI, regression equations derived from the relationship between a given VI and the measured LAI in a given year cannot necessarily be applied to other years. Because a VI value includes not only information about the LAI, but also information about the canopy structure, the coverage of the crop being investigated and other parameters [2], [20]. In other words, even if the same crop is cultivated at the same sites in different years, the potential of a particular VI for LAI estimation might change if the cultivation conditions are different or the reflectance data source is different (e.g., satellite, airborne remote sensing or ground-based data source). Furthermore, the major limitation of VIs, especially the NDVI based on the red and near infrared (NIR) portion of the spectrum, is that they asymptotically saturate above a certain biomass density or LAI value [21]. Hyperspectral remote sensing technology provides the possibility of investigating indices based on narrow bands across the whole spectrum, rather than the red and NIR bands only [22]. Studies have shown that the wavelengths 705 and $750 \mathrm{~nm}$, which are located in the red edge, can alleviate the problem of the saturation of VIs above a certain value of the LAI [23], and that narrow band VIs can overcome the saturation problem in biomass estimation by seeking the most correlated band combination to characterize the indices [22]. In this study, we evaluated three band-selection approaches: 1) the conventional approach (based on the reflectance at 670 and $800 \mathrm{~nm}$ ); 2) the red edge approach (based on the reflectance at 705 and $750 \mathrm{~nm}$ ); and 3) the best correlated approach (which selects the band combination that makes the VI most correlated with LAI through band-by-band computation).

In this context, the main purpose of this paper is to suggest a simple and accurate spectral index that is suitable for winter wheat LAI estimation. Empirical regression models for estimating winter wheat LAI using the aforementioned VIs were compared at a regional scale to achieve the following objectives: 1) to use hyperspectral and ground measured spectra to establish relationships between LAI measurements collected over fields and selected spectral indices; 2) to improve the indices' prediction capability by using different band-selection approaches; and 3) to validate the potential of these indices for LAI predictions and also to assess the influence of bandselection approaches on the accuracy of predictions based on the indices.

\section{Materials And Methods}

\section{A. Study Area and Data}

The study area was located at the National Experiment Station for Precision Agriculture $\left(40^{\circ} 10^{\prime} \mathrm{N}, 116^{\circ} 2^{\prime} \mathrm{E}\right)$, Beijing, China. This station is used for precision agriculture research and covers an area of $1667000 \mathrm{~m}^{2}$. The mean annual rainfall in the study area is $507.7 \mathrm{~mm}$ and the mean annual temperate is $13.8^{\circ} \mathrm{C}$ [23]. Winter wheat is one of the most important crops in China [24], [25], and is sown at this station almost every year specifically with the aim of performing precision agriculture research on this important crop. For this study, we used the field measurements conducted during two field campaigns on the winter wheat crops occurring in this area. In the first campaign, carried out during the 2002 winter wheat growing season, we collected airborne hyperspectral data and LAI ground measurements; while in the second campaign, we measured ground spectra and the corresponding LAI values during the 2014 winter wheat growing season. Using spectra collected in different years with different methods (airborne measurements in 2002 and ground-based measurements in 2014), a comprehensive analysis of the predictive ability of the indices was made.

1) Hyperspectral Spectra and Corresponding LAI Measurements: In the 2002 campaign, winter wheat was cultivated within 48 fields, each of size $32.4 \mathrm{~m} \times 30.0 \mathrm{~m}$. Three flights were performed over the test site, respectively, on April 18, May 17, and May 31, during which hyperspectral images were acquired by a pushbroom hyperspectral imager $(\mathrm{PHI})$. PHI is an array-pushing imaging spectrometer with a spectral resolution less than $5 \mathrm{~nm}$, spanning wavelengths of 405-835 nm and 126 bands [26], [27]. The flying heights varied between 1000 and $1200 \mathrm{~m}$ and the flight path covered the whole experimental station, meanwhile the spatial resolution of the corrected PHI images was $1 \mathrm{~m}$. Radiometric correction was performed using the band-by-band moment matching method and the empirical linear method was used to retrieve reflectance from digital number $(\mathrm{DN})$ of the images. The images were then geometrically corrected using ground control points. Afterward, the Savitzky-Golay filtering was performed using ENVI software to further improve the quality of PHI images [28].

Winter wheat leaves were sampled and recorded at three times corresponding to the flight tests. In each field, the sampling was performed within a $1 \mathrm{~m} \times 1 \mathrm{~m}$ plot and the location of the plot was recorded using GPS equipment (Trimble DSM 232 DGPS) with accuracy of $0.2 \mathrm{~m}$. The leaf areas of winter wheat were then measured in the laboratory to work out the LAI. Four invalid samples collected on May 31, 2002 were omitted because their LAI values were zero; the final dataset, therefore, consisted of 140 samples (a total of $48 \times 3=144$ minus the four samples that were omitted). As the GPS measurements allowed us to locate an LAI sampling plot in the PHI images, we extracted corresponding image spectra of the plots to conduct modeling analyses between the PHI spectra and the measured LAIs. Three images acquired during the 2002 flights are shown in Fig. 1: the 48 ground-measured plots are marked 


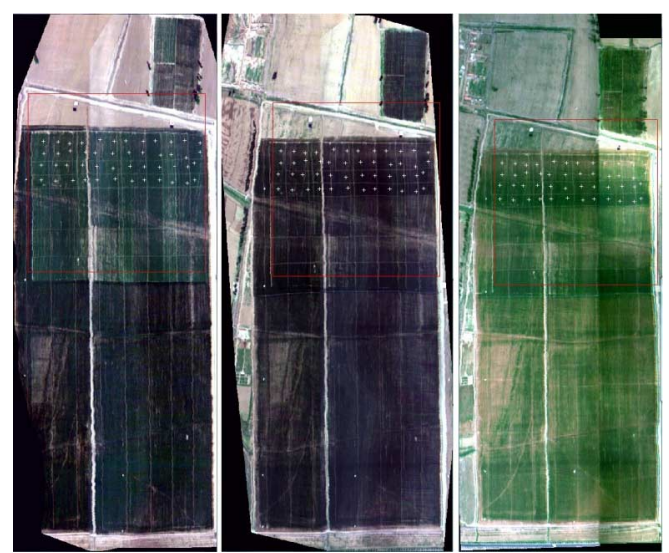

Fig. 1. PHI images acquired during the 2002 flights. From left to right: the images acquired on April 18, May 17, and May 31.

by white crosses and the area covered by the plots is outlined by red rectangles.

2) Ground Spectra and Corresponding LAI Measurements: In the 2014 campaign, winter wheat was cultivated within 13 fields, each of size $7.0 \mathrm{~m} \times 7.5 \mathrm{~m}$. Four replicated measurements of ground spectra and LAI were made-one each on April 14, April 23, May 5, and May 28. Canopy radiance data were measured using a portable field spectroradiometer (FieldSpec-FR2500, ASD, USA) at a distance of about $130 \mathrm{~cm}$ above the ground surface by maintaining the same viewing geometry (nadir view) to minimize directional effects resulting from properties of the target with a directional set-up. The canopy radiances were acquired between 350 and $2500 \mathrm{~nm}$ using an integration time of $50 \mathrm{~ms}$ and a spectral resolution of $1 \mathrm{~nm}$ and then converted into absolute reflectance by using a NIST calibrated panel (Spectralon-Sphere Optics Inc., Durham, NH, USA) to derive absolute reflectance spectra. Ten spectra for each wheat plot were collected and then averaged for more accurate analysis. Winter wheat LAI measurements in 2014 were conducted in the same way as for the 2002 campaign.

\section{B. Vegetation Indices}

The aim of this study was to find indices that can be used to estimate winter wheat LAI and to improve the accuracy of estimates using these indices. There were two main problems: 1) the selection of the VIs and 2) the selection of the bands to calculate the indices. Regarding band selection, some studies suggested that only a limited number of bands are necessary for canopy variables estimation [29], [30]. According to Darvishzadeh et al. [31], the full hyperspectral resolution is not automatically more advantageous than a carefully multispectral band selection for canopy variables estimation. Redundancy of spectral data and uncertainties attached to reflectance measurements with high noise levels in some hyperspectral bands may degrade the retrieval process [32].

In this study, we used the NDVI, the MSR, and the MSAVI to estimate LAI. The NDVI is the most used VI and was developed by Rouse et al. [17]. It has been widely accepted by researchers as a benchmark for comparing alternative inversion algorithms.
Despite the intensive use of NDVI, differences in LAI for LAI $>3$ cannot be resolved using NDVI values [33]. There are more effective hyperspectral vegetation indices (HVIs) that can be candidates for developing LAI estimation methods [34]. For example, there is a relatively full list of HVIs that can be used to estimate plant LAI from Table II in the study of Gong et al. [35] and Table 5.2 in the study of Ruiliang and Peng [36]. Some of the indices were developed due to the saturation problem of NDVI (such as MSR, SR, and EVI), while the others were aimed at resisting to the environmental factors (such as MSAVI, SAVI, and TSAVI). It was not practical to exhaust all these VIs in this study of winter wheat LAI estimation from ground and hyperspectral observations, therefore, besides the benchmark index NDVI, the MSR was chosen as a representative of the indices with the ability to alleviate the saturation problem [18], and MSAVI was chosen as a representative of the indices with insensitivity to soil effects on the canopy spectra [19]. Table I lists all three VIs together with their definitions and references to the relevant papers.

Three band-selection approaches were used to formulate VIs in this study: the conventional approach and the best correlated approach. Vegetation reflectance at $670 \mathrm{~nm}$ corresponds to the maximum absorption of the red band and the reflectance at $800 \mathrm{~nm}$ corresponds to the maximum reflection region of the NIR band [4]. Therefore, the conventional algorithm uses the reflectance at 670 and $800 \mathrm{~nm}$ to calculate VIs. Chaoyang et al. have shown that the use of the wavelengths 705 and $750 \mathrm{~nm}$, which are located within the red edge, could alleviate the saturation of VIs with increasing LAI [23]. In response to this, the first improved approach we investigated was the red edge approach, which used the reflectance values at 705 and $750 \mathrm{~nm}$ to form the revised indices instead of 670 and $800 \mathrm{~nm}$. The second improved approach (the best correlated approach) was specifically designed for narrow-band hyperspectral data [22]. With the best correlated approach, we used every possible combination of bands to find the highest correlation between the VIs and the LAI; subsequently, we used the indices with the highest correlation to formulate regression equations between VIs and LAI. Indeed, the calculation of coefficients in the MSAVI formula (Table I) is closely related to the red and NIR bands, and therefore, in order to follow the principle of MSAVI, we adopted the wavelength range $600-800 \mathrm{~nm}$ to perform bandby-band calculations with the best correlated approach instead of the whole spectrum of hyperspectral and ground-measured reflectance.

\section{Validation Scheme}

In order to make a thorough analysis of the dataset, we made three groups of tests and built estimation models by using the 2002 dataset, the 2014 dataset, and the 2002-2014 pooled dataset, respectively.

A $k$-fold cross-validation procedure was used to evaluate the performance of the estimation models [27]. The entire dataset was divided into $k$ mutually exclusive groups following a $k$-fold cross-validation partitioning design. In our case, the dataset was split randomly and evenly into four $(k=4)$ sets, and the LAI values for each quarter of the dataset were estimated by models 
Thisarticlehasbeenacceptedforinclusioninafutureissueofthisjournal.Contentisfinalaspresented,withtheexceptionofpagination.

TABLE I

DEFinitions AND Formulas of VIs InVESTIGATEd In This StUdy

\begin{tabular}{cccc}
\hline Index & Abbr. & Formula & Reference \\
\hline $\begin{array}{c}\text { Normalized difference } \\
\text { vegetation index }\end{array}$ & NDVI & $N D V I=\frac{\rho_{\text {nir }}-\rho_{\text {red }}}{\rho_{\text {nir }}+\rho_{\text {red }}}$ & [17] \\
\hline $\begin{array}{c}\text { Modified simple ratio index } \\
\text { Modified soil-adjusted } \\
\text { vegetation index }\end{array}$ & MSR & $M S R=\frac{\rho_{\text {nir }} / \rho_{\text {red }}-1}{\sqrt{\rho_{\text {nir }} / \rho_{\text {red }}+1}}$ & {$[18]$} \\
\hline & & $M S A V I=\frac{2 * \rho_{\text {nir }}+1-\sqrt{\left(2 * \rho_{\text {nir }}+1\right)^{2}-8 *\left(\rho_{\text {nir }}-\rho_{\text {red }}\right)}}{2}$ & {$[19]$} \\
\hline
\end{tabular}

built using VIs and the LAI values of the remaining samples. The dataset from the 2002 campaign consisted of 140 samples; each sample with VIs is calculated from the PHI hyperspectral reflectance and corresponding ground-measured LAI data. For each type of VI, 105 samples were used to build the calibration model. The equation was then inverted to estimate the LAI of the remaining 35 samples, while the ground-measured LAI values of these 35 samples were used to validate the estimation results. For estimations of the LAI using one particular type of VI, we developed four individual models, each using one quarter of the total dataset (in rotation) as validation data. Note that each estimation model built with different types of VIs and different band-selection approaches used the same $k$-fold partitions; this allowed us to make comparisons between the LAIs estimated using different VIs and to evaluate the influence of the different band-selection approaches on the VIs. The 2014 campaign dataset consisted of 52 samples, each with groundmeasured reflectance and LAI data. As for the 2002 dataset, the same cross-validation procedure was carried out for the 2014 dataset and 2002-2014 pooled dataset.

This type of validation reduced the dependence on a single random partition into validation datasets. It also guaranteed that all samples were used for both training and validation with each sample used for validation exactly once. Values of the coefficient of determination $\left(\mathrm{R}^{2}\right)$ and root-mean-square error (RMSE) were selected as indicators of the accuracy of the statistical models.

\section{RESULTS AND DisCUSSION}

\section{A. Relationships Between VIs and LAI}

As mentioned in Section II-B, the conventional approach imposes the reflectance at 670 and $800 \mathrm{~nm}$ to calculate VIs, and the first improved approach (the red edge approach) uses the reflectance at 705 and $750 \mathrm{~nm}$ instead; while the second improved approach (the best correlated approach) uses the NDVI, MSR, and MSAVI formulae with every possible band combination. Correlation coefficients between the LAI and these indices are mapped in Fig. 2. These maps were used to decide the best correlated bands for each index. In the case of the 2002 experiment, the hyperspectral reflectance band pair used in the NDVI, MSR, and MSAVI formulae was $(700,724 \mathrm{~nm})$. For the 2014 experiment, the bands used for the ground-measured reflectance in the NDVI, MSR and MSAVI formulae were, respectively, (611, $639 \mathrm{~nm}),(611$,
$639 \mathrm{~nm})$, and $(735,736 \mathrm{~nm})$; Whereas, in the 2002-2014 pooled case, the bands selected to calculate NDVI, MSR, and MSAVI were, respectively, (708, $724 \mathrm{~nm}),(708,724 \mathrm{~nm})$, and $(714,772 \mathrm{~nm})$. Although the first ranked best correlated bands for NDVI and MSR in the 2014 case centered at (611, $639 \mathrm{~nm}$ ) and the first ranked best correlated bands for MSAVI in 2002-2014 pooled case centered at (714, $772 \mathrm{~nm})$, we caution that, the three indices yielded significant correlation coefficient based on many band combinations within the red edge region (700-750 nm), which was clearly demonstrated in Fig. 2.

Once the band selection using the best correlated approach was completed, the three investigated VIs were calculated using the conventional approach, the red edge approach, and the best correlated approach. Empirical regression models were built using the LAI and VIs, and the resulting equations are presented in Table II. The relationships between LAI and the VIs exhibited a considerable scatter, with the values of $\mathrm{R}^{2}$ ranging from 0.4807 (for NDVI based on the conventional approach in the 2014 experiment) to 0.8673 (for MSAVI based on the best correlated approach in the 2014 experiment). This scatter was mainly caused by the chlorophyll content variation and the effects of other canopy characteristics. In fact, these indices are designed to measure vegetation greenness, in which chlorophyll content as well as the amount of green leaves plays a crucial role [4].

From the perspective of the band-selection approach, the best correlated approach (which chooses the most highly correlated bands through band-by-band computation) best related the VIs to the LAI in both experiments. Our results for the 2002 experiment showed that the conventional approach (using the wavelengths 670 and $800 \mathrm{~nm}$ ) better captured the relationship between VIs and LAI than the red edge approach (using the wavelengths 705 and $750 \mathrm{~nm}$ ). Conversely, in the 2014 experiment, the red edge approach outperformed the conventional approach. These two approaches performed similar to the 2002-2014 pooled experiment.

From the perspective of the VI type, the three indices showed comparable sensitivity to the LAI when the same approach was used with the 2002 data and 2002-2014 pooled data. In the case of the 2014 experiment, the MSAVI gave the best fit for each approach - this contrasted with the indices derived from simulated data using PROSPECT and SAILH, among which MSR showed higher sensitivity to LAI than MSAVI and NDVI [4]. It can be explained by considering that the ground-measured spectra were influenced by the soil whereas the PROSPECT 

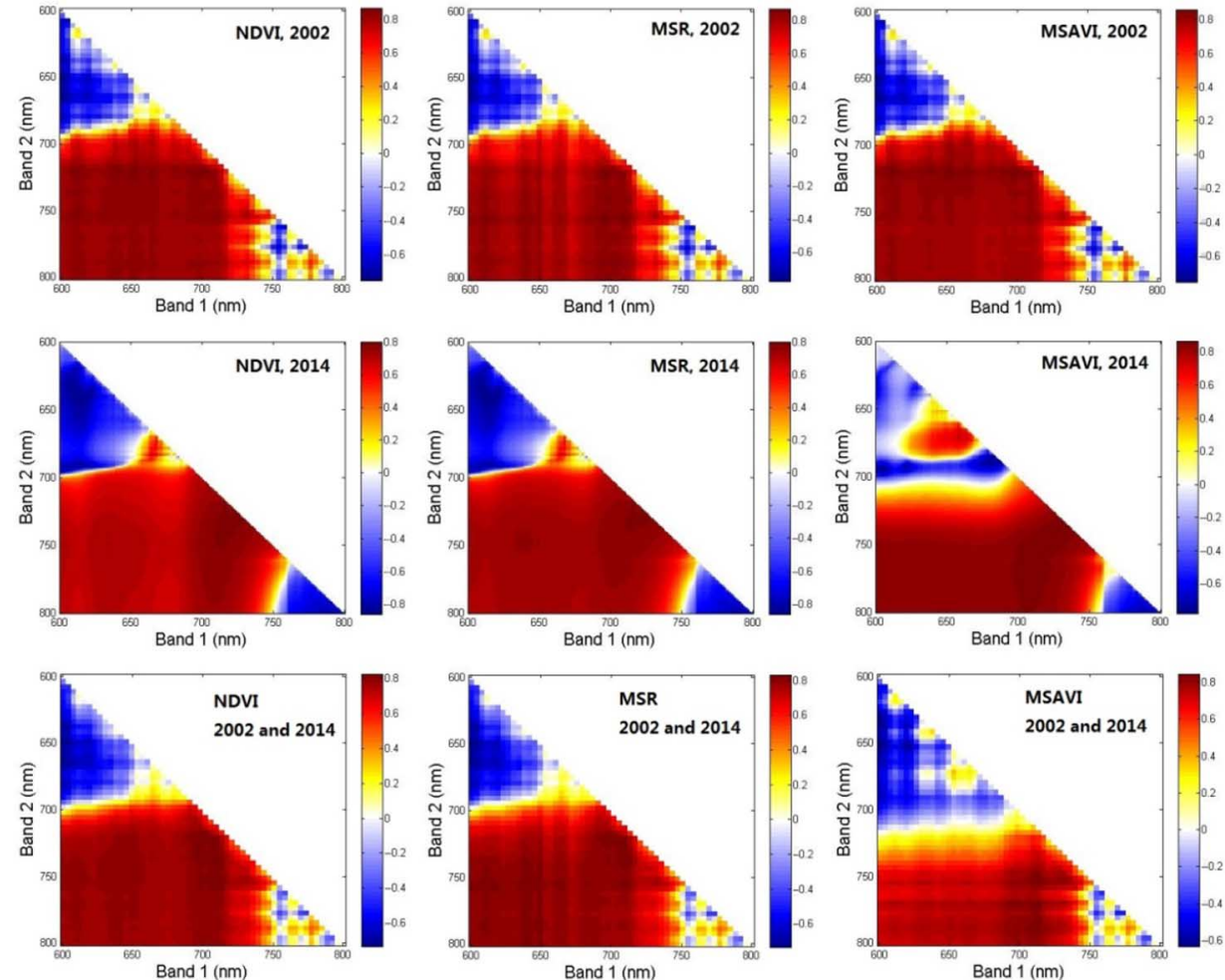

Fig. 2. Maps showing the correlation coefficients between LAI and VIs based on the NDVI, MSR, and MSAVI formulae. VIs were calculated using all possible band combinations spread across Band $1(600-800 \mathrm{~nm})$ and Band $2(600-800 \mathrm{~nm})$.

TABLE II

Statistical Analysis of the RELationship BetweEn LAI AND VIS

\begin{tabular}{|c|c|c|c|c|c|c|c|c|}
\hline & \multicolumn{2}{|c|}{$\begin{array}{c}2002 \\
\text { Calibration models } \\
\end{array}$} & & \multicolumn{2}{|c|}{$\begin{array}{c}2014 \\
\text { Calibration models }\end{array}$} & & \multicolumn{2}{|c|}{$\begin{array}{l}\text { 2002-2014 Pooled } \\
\text { Calibration models }\end{array}$} \\
\hline & $\begin{array}{l}\text { Statistical } \\
\text { equation }\end{array}$ & $\mathrm{R}^{2}$ & & $\begin{array}{l}\text { Statistic al } \\
\text { equation }\end{array}$ & $\mathrm{R}^{2}$ & & $\begin{array}{l}\text { Statistical } \\
\text { equation }\end{array}$ & $\mathrm{R}^{2}$ \\
\hline $\begin{array}{l}\text { NDVI } \\
(670,800)\end{array}$ & $\begin{array}{l}y=-0.0369 x^{2}+ \\
0.2898 x+0.3069\end{array}$ & 0.7507 & $\begin{array}{l}\text { NDVI } \\
(670,800)\end{array}$ & $\begin{array}{l}y=-0.0089 x^{2}+ \\
0.0957 x+0.6571\end{array}$ & 0.4807 & $\begin{array}{l}\text { NDVI } \\
(670,800)\end{array}$ & $\begin{array}{r}y=-0.0229 x^{2}+ \\
0.2147 x+0.4048\end{array}$ & 0.6691 \\
\hline $\begin{array}{l}\text { MSR } \\
(670,800)\end{array}$ & $y=1.273 x^{0.7643}$ & 0.7264 & $\begin{array}{l}\text { MSR } \\
(670,800)\end{array}$ & $\begin{array}{l}y=-0.1057 x^{2}+ \\
1.2548 x+1.0134\end{array}$ & 0.5585 & $\begin{array}{l}\text { MSR } \\
670,800)\end{array}$ & $\mathrm{y}=1.4087 \mathrm{x}^{0.707}$ & 0.6720 \\
\hline $\begin{array}{l}\text { MSAVI } \\
(670,800)\end{array}$ & $\begin{array}{l}y=-0.0318 x^{2}+ \\
0.2337 x+0.5024\end{array}$ & 0.7306 & $\begin{array}{l}\text { MSAVI } \\
(670,800)\end{array}$ & $y=0.4104 x^{0.3446}$ & 0.7916 & $\begin{array}{l}\text { MSAVI } \\
(670,800)\end{array}$ & $y=0.4119 x^{0.3706}$ & 0.6152 \\
\hline $\begin{array}{l}\text { NDVI } \\
(705,750)\end{array}$ & $\begin{array}{l}y=-0.025 x^{2}+ \\
0.2151 x+0.1612\end{array}$ & 0.7203 & $\begin{array}{l}\text { NDVI } \\
(705,750)\end{array}$ & $\begin{array}{l}y=-0.0147 x^{2}+ \\
0.1493 x+0.347\end{array}$ & 0.6745 & $\begin{array}{l}\text { NDVI } \\
(705,750)\end{array}$ & $\begin{array}{c}\mathrm{y}=-0.0105 \mathrm{x}^{2}+ \\
0.1524 \mathrm{x}+0.2421\end{array}$ & 0.6552 \\
\hline $\begin{array}{l}\text { MSR } \\
(705,750)\end{array}$ & $\begin{array}{l}y=-0.049 x^{2}+ \\
0.5136 x+0.1752\end{array}$ & 0.7188 & $\begin{array}{l}\text { MSR } \\
(705,750)\end{array}$ & $y=0.9843 x^{0.4373}$ & 0.6568 & $\begin{array}{l}\text { MSR } \\
(705,750)\end{array}$ & $\mathrm{y}=0.6883 \mathrm{x}^{0.6379}$ & 0.6335 \\
\hline $\begin{array}{l}\text { MSAVI } \\
(705,750)\end{array}$ & $\begin{array}{l}y=-0.0291 x^{2}+ \\
0.2308 x+0.3043\end{array}$ & 0.7043 & $\begin{array}{l}\text { MSAVI } \\
(705,750)\end{array}$ & $\begin{array}{l}y=-0.016 x^{2}+ \\
0.1572 x+0.1042\end{array}$ & 0.8403 & $\begin{array}{l}\text { MSAVI } \\
(705,750)\end{array}$ & $\begin{array}{c}y=-0.0089 x^{2}+ \\
0.1169 x+0.1471\end{array}$ & 0.6371 \\
\hline $\begin{array}{l}\text { NDVI } \\
(700,724)\end{array}$ & $\begin{array}{l}y=-0.0201 x^{2}+ \\
0.1859 x+0.0376\end{array}$ & 0.7960 & $\begin{array}{l}\text { NDVI } \\
(611,639)\end{array}$ & $\begin{array}{l}y=-0.0035 x^{2}+ \\
0.037 x-0.0104\end{array}$ & 0.8282 & $\begin{array}{l}\text { NDVI } \\
(708,724)\end{array}$ & $\begin{array}{r}y=-0.0079 x^{2}+ \\
0.1022 x+0.0573\end{array}$ & 0.7097 \\
\hline $\begin{array}{l}\text { MSR } \\
(700,724)\end{array}$ & $\begin{array}{l}y=-0.0323 x^{2}+ \\
0.3488 x+0.0131\end{array}$ & 0.7817 & $\begin{array}{l}\text { MSR } \\
(611,639)\end{array}$ & $\begin{array}{l}y=-0.0052 x^{2}+ \\
0.055 x-0.0166\end{array}$ & 0.8244 & $\begin{array}{l}\text { MSR } \\
(708,724)\end{array}$ & $\begin{array}{r}\mathrm{y}=-0.0114 \mathrm{x}^{2}+ \\
0.1755 \mathrm{x}+0.0727\end{array}$ & 0.7108 \\
\hline $\begin{array}{l}\text { MSAVI } \\
(700,724)\end{array}$ & $\begin{array}{l}y=-0.0287 x^{2}+ \\
0.2423 x+0.1129\end{array}$ & 0.7963 & $\begin{array}{l}\text { MSAVI } \\
(735,736)\end{array}$ & $\begin{array}{l}y=-0.0004 x^{2}+ \\
0.0042 x+0.0017\end{array}$ & 0.8673 & $\begin{array}{l}\text { MSAVI } \\
(714,772)\end{array}$ & $\begin{array}{c}y=-0.01 x^{2}+ \\
0.1267 x+0.1223\end{array}$ & 0.7454 \\
\hline
\end{tabular}

* "x" refers to LAI and "y" refers to VI; VIs are denoted by name and band wavelengths (in nm): e.g., NDVI (670, 800) indicates the NDVI calculated using reflectance at 670 and $800 \mathrm{~nm}$.

and SAILH simulated spectra were not. This may have led to MSAVI being the most sensitive index to LAI in the 2014 experiment.

\section{B. Comparing the LAI Estimation Performance of the Indices}

Predictive equations were derived from the statistical relationships between the spectral indices (NDVI, MSR, and
MSAVI) using hyperspectral and ground-measured spectra as well as ground-measured winter wheat LAI. The predictive equations were applied to PHI images and ASD spectra collected at different dates during the winter wheat growing season to represent the early vegetative, active, and reproductive growth stages. Estimation results were assessed using ground truth LAIs following the $k$-fold cross-validation procedure mentioned above. 


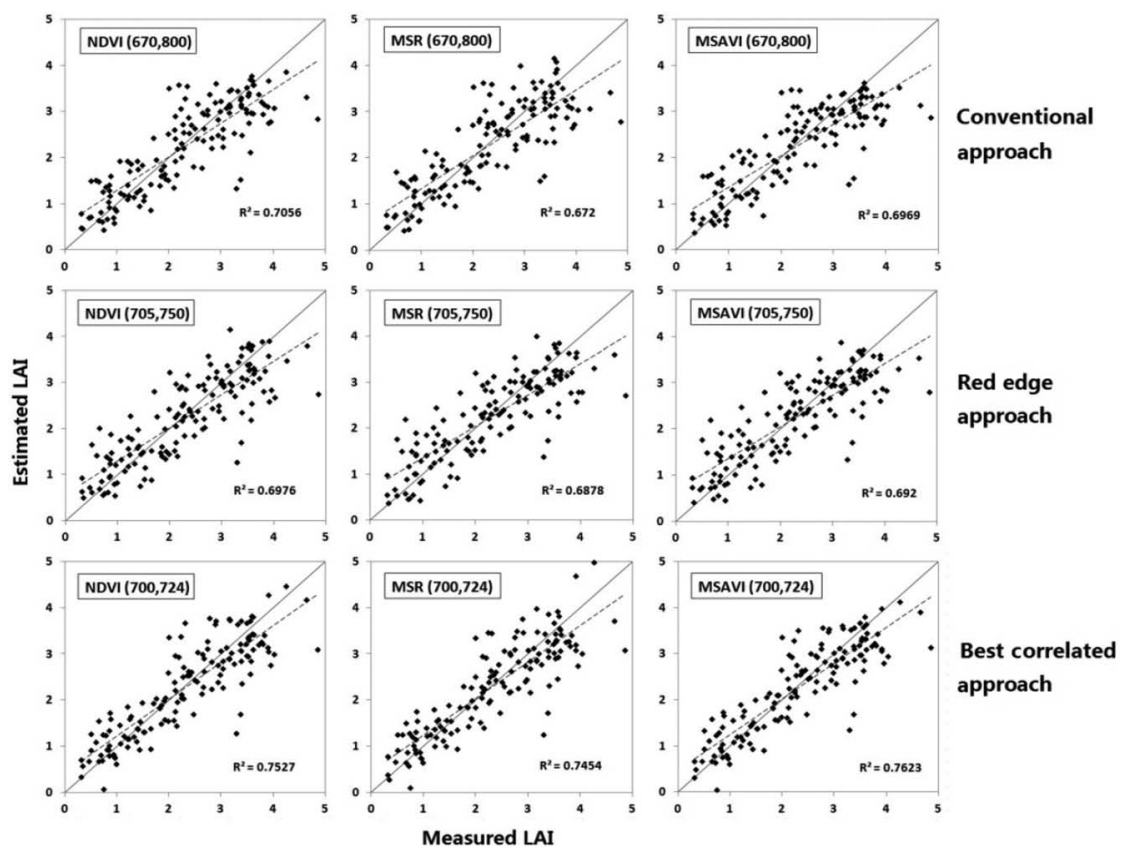

Fig. 3. Comparison between measured LAI and LAI estimated from PHI images of winter wheat from the 2002 campaign using predictive equations determined from NDVI, MSR, and MSAVI using three different approaches. VIs are denoted by name and band wavelengths (in nm): e.g., NDVI (670, 800) indicates the NDVI calculated using reflectance at 670 and $800 \mathrm{~nm}$.

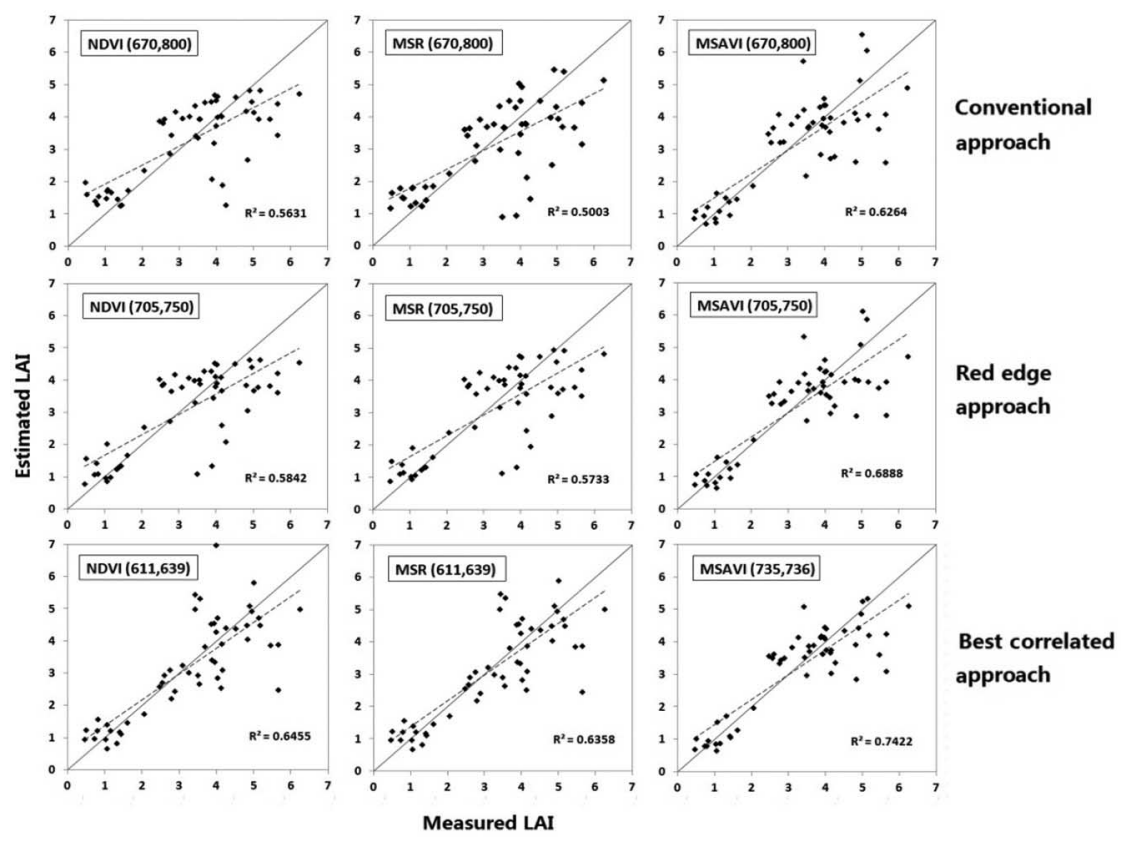

Fig. 4. Comparison between measured LAI and LAI estimated from ground-measured data of winter wheat from the 2014 campaign using predictive equations determined from NDVI, MSR, and MSAVI using three different approaches. VIs are denoted by name and band wavelengths (in nm): for example, NDVI (670, 800) indicates the NDVI calculated using reflectance at 670 and $800 \mathrm{~nm}$.

In Fig. 3, values of LAI estimated using PHI spectra are plotted against field LAI measurements from the 2002 campaign. Fig. 4 compares LAI estimates derived from ground-measured spectra and LAI measurements collected during the 2014 campaign. The 2002-2014 pooled estimation results against in situ LAI measurements are shown Fig. 5. Table III lists the RMSE between the estimated and measured LAI values of each estimation model. In Figs. 3-5, VIs are denoted by their names and band wavelengths $(\mathrm{nm})$ : for example, NDVI $(670,800)$ indicates the VI calculated using reflectance at 670 and $800 \mathrm{~nm}$ with the NDVI formula. To note that, indices based on the red edge approach and the best correlated approach did not strictly follow the formulae listed in Table I because bands at the red edge or other wavelengths were used to replace $\rho_{\text {nir }}$ and $\rho_{\text {red }}$. In general, Figs. 3-5 showed that there was a very good agreement between the predicted LAI values and the ground truth values. For the 2002 experiment, the coefficient of determination $\left(\mathrm{R}^{2}\right)$ ranged from 0.6720 to 0.7623 with an RMSE less than 


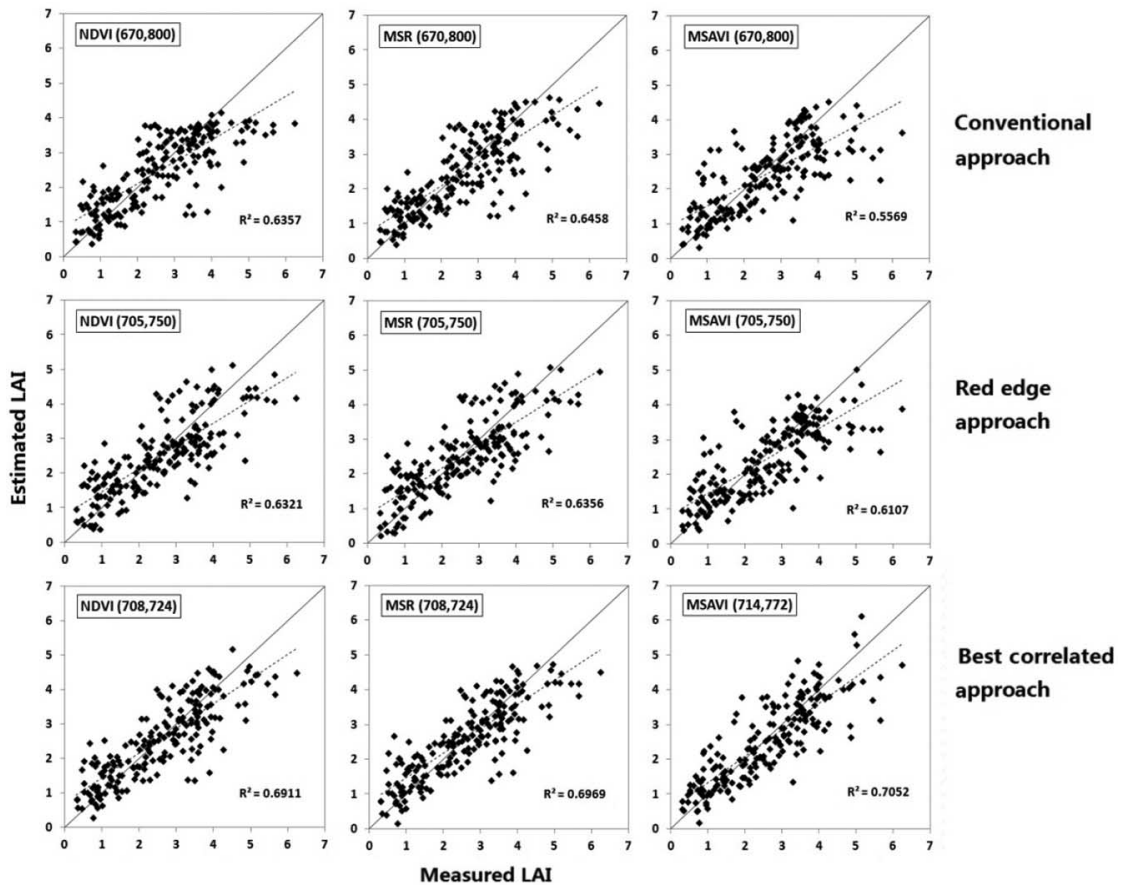

Fig. 5. Comparison between measured LAI and LAI estimated from the 2002-2014 pooled data using predictive equations determined from NDVI, MSR, and MSAVI using three different approaches. VIs are denoted by name and band wavelengths (in nm): i.e., NDVI (670, 800) indicates the NDVI calculated using reflectance at 670 and $800 \mathrm{~nm}$.

TABLE III

RMSE BetweEn Estimated LAI AND MEAsured LAI

\begin{tabular}{l|l|c|c|c}
\hline \multicolumn{2}{l|}{} & 2002 RMSE & 2014 RMSE & $\begin{array}{c}2002-2014 \\
\text { Pooled RMSE }\end{array}$ \\
\hline \multirow{2}{*}{$\begin{array}{l}\text { Conventional approach } \\
(670,800 \mathrm{~nm})\end{array}$} & NDVI & 0.5983 & 1.0270 & 0.7947 \\
\cline { 2 - 5 } & MSR & 0.6305 & 1.1245 & 0.7838 \\
\cline { 2 - 5 } & MSAVI & 0.6051 & 0.9783 & 0.8832 \\
\hline \multirow{2}{*}{$\begin{array}{l}\text { Red edge approach (705, } \\
750 \mathrm{~nm})\end{array}$} & NDVI & 0.6065 & 1.0184 & 0.7957 \\
\cline { 2 - 5 } & MSR & 0.6138 & 1.0366 & 0.7898 \\
\cline { 2 - 5 } & MSAVI & 0.6097 & 0.8778 & 0.8273 \\
\hline \multirow{2}{*}{$\begin{array}{l}\text { Best correlated approach (best } \\
\text { correlated bands) }\end{array}$} & NDVI & 0.5489 & 0.9733 & 0.7269 \\
\cline { 2 - 5 } & MSR & 0.5567 & 0.9927 & 0.7185 \\
\cline { 2 - 5 } & MSAVI & 0.5367 & 0.7928 & 0.7151 \\
\hline
\end{tabular}

0.6305. For the 2014 case, $\mathrm{R}^{2}$ ranged from 0.5003 to 0.7422 with an RMSE less than 1.1245; whereas, for the 2002-2014 pooled experiment, $\mathrm{R}^{2}$ ranged from 0.5569 to 0.7052 with an RMSE less than 0.8832 . The results revealed significant differences in the behavior of the indices and in the superiority of the band-selection approaches.

The influence of the band-selection approaches is well illustrated by comparing graphs within the same columns in Figs. 3-5. The best correlated approach (the band-by-band selection approach) improved the predictive ability of HVIs, generating the highest $\mathrm{R}^{2}$ and the lowest RMSE among the three approaches in 2002, 2014, and 2002-2014 pooled tests. The indices calculated using the red edge approach (705 and $750 \mathrm{~nm}$ ) outperformed those calculated using the conventional approach (670 and $800 \mathrm{~nm}$ ) in the 2014 test, but in the 2002 test, the red edge approach did not produce a significant improvement compared to the conventional approach. In order to further compare the conventional approach and the red edge approach, we made a statistical study to count the proportion of the 2002 and 2014 datasets for which LAI $>3$ and to determine the range
TABLE IV

Proportion of SAMPLES With LAI > 3 AND RANGE OF LAi VAlues FOR THE 2002 AND 2014 DATASETS

\begin{tabular}{l|c|c}
\hline & 2002 & 2014 \\
\hline Proportion of samples with LAI $>3$ & $32.14 \%$ & $61.54 \%$ \\
\hline LAI value range & $0.31-4.86$ & $0.45-6.24$ \\
\hline
\end{tabular}

of LAI values in these datasets (Table IV). Given that in VI-LAI regression models, indices tend to saturate when the value of the LAI is greater than 3 , we took 3 as the threshold value when determining the LAI $>3$ proportion. Table IV showed that compared to 2002, the range of LAI values in 2014 was wider and the proportion of samples for which LAI $>3$ was larger. This leads to a deduction: the red edge approach alleviates the saturation problem over intermediate-to-high density canopies (where LAI > 3), but the conventional approach better captures the correlation between indices and LAI over sparse canopies (LAI $<3$ ). This was consistent with the results of the study by Wu et al., which showed that in VI-LAI models, VIs calculated using the $(670,800 \mathrm{~nm})$ wavelengths better responded to lowto-intermediate LAI values than those calculated using (705, $750 \mathrm{~nm})$, on the other hand, the $(705,750 \mathrm{~nm})$ band pair reduces saturation for intermediate-to-high values of LAI [23]. It can be explained by the influence of chlorophyll content according to the study of Haboudane et al. [4]: the integration of bands in the conventional approach $(670,800 \mathrm{~nm})$ are highly correlated to leaf and canopy chlorophyll content and easy to be hindered at high levels of canopy chlorophyll content. As the canopy chlorophyll content was higher in the case of 2014 than in 2002, consequently, the conventional approach was outperformed by the red edge approach in the case of 2014. 
Comparison between the graphs in the same rows in Figs. 3-5 revealed discrepancies of the three indices tested in this paper. As shown in Fig. 3, in 2002 results, all the indices followed the one-to-one line all along. These results were quite different from those in the 2014 test: as can be seen from Fig. 4, the three indices behaved in two distinct ways. During the early vegetative stage, the MSAVI closely followed the one-to-one line while the NDVI and MSR overestimated the wheat canopy LAI; during the active growth and reproductive periods, the MSAVI followed the one-to-one line less closely while the NDVI and MSR underestimated the wheat canopy LAI. Regards 2002-2014 pooled results, Fig. 5 showed that, when using the same VI and the same band-selection approach, the models gave medium accuracy between the 2002 and 2014 results.

Consequently, from the analysis of the $\mathrm{R}^{2}$ and RMSE values, MSR demonstrated medium LAI predictive power in the 2002, 2014, and 2002-2014 pooled tests compared to the other two indices when using the same approach, because the MSR was the most affected by chlorophyll variability among the three indices tested. It is true that the MSR is meant to improve the linearity and overcome the saturation limits, but only at high levels of canopy chlorophyll content. Thus, MSR is more applicable to forestry than to agriculture, which is consistent with the study of Haboudane et al. [4]. The NDVI and MSAVI are resistant to chlorophyll content variability, and they showed similar behaviors when using the same approach in the 2002 test, but in the 2014 test, the latter outperformed the former having higher accuracy and being better able to solve the underestimation and overestimation problems. The different data sources led to differences in the estimation behavior of NDVI and MSAVI: in the case of 2002 based on PHI hyperspectral spectra, the three indices showed comparable predictive power, while in the case of 2014 based on ground-measured spectra, MSAVI showed a significant advantage over NDVI. This was due to the influence of the soil factor, which affects ground observations more than airborne observations, explaining the excellent results produced by the MSAVI using the 2014 data. Regarding the 2002-2014 pooled test, however, as shown in Fig. 5, NDVI provided robust estimation accuracies based on every band-selection approach ( $\mathrm{R}^{2}$ ranged from 0.6321 to 0.6911 ), while MSAVI behaved differently when band-selection approach varied $\left(\mathrm{R}^{2}\right.$ ranged from 0.5569 to 0.7052 ).

The result that the MSAVI was the best index to estimate LAI values obtained for the 2014 test was consistent with the results of Broge's study [19], but the result that the MSAVI as well as the NDVI and MSR underestimated the LAI when the LAI exceeds 3 contrasted with the predictive equations derived from simulated data using PROSPECT and SAILH [4]. Indeed, we noticed that using the same indices (NDVI, MSR, and MSAVI), approaches based on ground and airborne measurements had a tendency to underestimate the LAI, while approaches based on simulated data tended to overestimate the LAI. Overall, our results for the 2 years of measurements demonstrate that the equations relating the investigated indices to winter wheat canopy reflectance are reasonable. In all the three cases (2002, 2014, and 2002-2014 pooled case), the best prediction was produced by the MSAVI based on the best correlated approach.

\section{CONCLUSION}

In this paper, we have studied winter wheat LAI estimation based on the use of predictive equations derived from airborne and ground measurements made over winter wheat canopies. Three indices (NDVI, MSR, and MSAVI) and three band-selection approaches (the conventional approach, the red edge approach, and the best correlated approach) were applied to hyperspectral and ground-measured spectra as well as ground LAI measurements. The aim was to investigate the relative ability of band-selection approaches and hyperspectral VIs on estimating winter wheat LAI.

Our study shows that hyperspectral VIs had different predictive behaviors when calculated with different data sources: NDVI gave the most robust LAI estimation across different sites, years and sensors, but it was not suitable for estimating the LAI of intermediate-to-dense canopies as it exhibited a clear saturation when LAI $>3$; MSAVI was superior when using ground-measured spectra, which were more influenced by the soil compared with hyperspectral spectra, as it gave the best solution to the underestimation problem for low-tointermediate LAI values and to the overestimation problem for intermediate-to-high LAI values, especially when applied to the 2014 case; MSR performed moderately among the three indices in each case, thus it was not a perfect solution to the saturation problem as it demonstrated more severe scattering and lower predictive accuracy than the NDVI on canopies that were not dense enough. In addition, the results reported in this paper prove that VIs calculated using the red edge approach (705, $750 \mathrm{~nm}$ ) was not necessarily better correlated with LAI than those calculated using the conventional approach (670 $800 \mathrm{~nm})$, because the former was more sensitive to dense canopies with high chlorophyll content level, while the latter was more responsive to sparse canopies. During the winter wheat growing season, the LAI normally ranges from 0 to 7 , meaning that sparse and dense canopies are of the same importance. The best correlated approach explained about $10 \%$ greater accuracy than the conventional approach and the red edge approach, significantly improved the predictive power of VIs by working out which bands were the most correlated with LAI values. Meanwhile, through band-by-band calculation, the best correlated approach revealed the significant correlation between the LAI and VIs based on bands within the red edge region. To sum up, one index is not necessarily suitable for use in all LAI predictions. Future work should consider the relative importance of saturation, chlorophyll variability, and environmental factors such as soil, atmosphere, and background when establishing LAI estimation functions using VIs. These results support the use of MSAVI and NDVI based on red edge region to estimate winter wheat LAI, establishing a step toward improved use of hyperspectral and ground-measured data for predicting values of the LAI at the regional scale.

\section{ACKNOWLEDGMENT}

The authors thank the field campaign at the National Experiment Station for Precision Agriculture and the staff for managing the flights and crop planting efficiently. The help given by $\mathrm{C}$. Wu and $\mathrm{G}$. Yin in guiding the data analysis is much 
appreciated. They also thank the anonymous reviewers for their valuable suggestions and comments.

\section{REFERENCES}

[1] M. Marshall and P. Thenkabail, "Developing in situ non-destructive estimates of crop biomass to address issues of scale in remote sensing," Remote Sens., vol. 7, no. 1, pp. 808-835, 2015.

[2] L. Jiangui, E. Pattey, and G. Jégo, "Assessment of vegetation indices for regional crop green LAI estimation from Landsat images over multiple growing seasons," Remote Sens. Environ., vol. 123, pp. 347-358, 2012.

[3] M. Moroni, E. Lupo, E. Marra, and A. Cenedese, "Hyperspectral image analysis in environmental monitoring: Setup of a new tunable filter platform," Procedia Environ. Sci., vol. 19, pp. 885-894, 2013.

[4] D. Haboudane, J. R. Miller, E. Pattey, P. J. Zarco-Tejada, and I. B. Strachan, "Hyperspectral vegetation indices and novel algorithms for predicting green LAI of crop canopies: Modeling and validation in the context of precision agriculture," Remote Sens. Environ., vol. 90, no. 3, pp. 337-352, 2004.

[5] A. Bsaibes et al., "Albedo and LAI estimates from FORMOSAT-2 data for crop monitoring," Remote Sens. Environ., vol. 113, no. 4, pp. 716-729, 2009.

[6] R. Darvishzadeh, A. Skidmore, M. Schlerf, C. Atzberger, F. Corsi, and M. Cho, "LAI and chlorophyll estimation for a heterogeneous grassland using hyperspectral measurements," ISPRS J. Photogramm. Remote Sens., vol. 63, no. 4, pp. 409-426, 2008.

[7] P. Hansen and J. Schjoerring, "Reflectance measurement of canopy biomass and nitrogen status in wheat crops using normalized difference vegetation indices and partial least squares regression," Remote Sens. Environ., vol. 86, no. 4, pp. 542-553, 2003.

[8] F. Baret et al., "LAI, fAPAR and fCover CYCLOPES global products derived from VEGETATION: Part 1: Principles of the algorithm," Remote Sens. Environ., vol. 110, no. 3, pp. 275-286, 2007.

[9] Y. Knyazikhin, J. Martonchik, R. Myneni, D. Diner, and S. Running, "Synergistic algorithm for estimating vegetation canopy leaf area index and fraction of absorbed photosynthetically active radiation from MODIS and MISR data," J. Geophys. Res.: Atmos. (1984-2012), vol. 103, no. D24, pp. 32257-32275, 1998.

[10] J. Hanes, Biophysical Applications of Satellite Remote Sensing. New York, NY, USA: Springer, 2013.

[11] H. Wenjiang, H. Muyi, L. Liangyun, W. Jihua, Z. Chunjiang, and W. Jindi, "Inversion of the severity of winter wheat yellow rust using proper hyper spectral index," Trans. Chin. Soc. Agric. Eng., vol. 21, no. 4, pp. 97-103, 2005.

[12] R. Pu and P. Gong, "Wavelet transform applied to EO-1 hyperspectral data for forest LAI and crown closure mapping," Remote Sens. Environ., vol. 91, no. 2, pp. 212-224, 2004.

[13] Y. Gaofei et al., "Improving leaf area index retrieval over heterogeneous surface by integrating textural and contextual information: A case study in the Heihe river basin," IEEE Geosci. Remote Sens. Lett., vol. 12, no. 2, pp. 359-363, 2015.

[14] P. S. Thenkabail, M. K. Gumma, P. G. Teluguntla, and M. Ilyas, "Hyperspectral remote sensing of vegetation and agricultural crops," Photogramm. Eng. Remote Sens., vol. 80, no. 4, pp. 697-709, 2014.

[15] P. S. Thenkabail, R. B. Smith, and E. De Pauw, "Evaluation of narrowband and broadband vegetation indices for determining optimal hyperspectral wavebands for agricultural crop characterization," Photogramm. Eng. Remote Sens., vol. 68, no. 6, pp. 607-622, 2002.

[16] R. Darvishzadeh, C. Atzberger, A. Skidmore, and M. Schlerf, "Mapping grassland leaf area index with airborne hyperspectral imagery: A comparison study of statistical approaches and inversion of radiative transfer models," ISPRS J. Photogramm. Remote Sens., vol. 66, no. 6, pp. 894 906, 2011.

[17] J. Rouse, Jr., R. Haas, J. Schell, and D. Deering, "Monitoring vegetation systems in the great plains with ERTS," NASA Spec. Publ., vol. 351, p. 309, 1974.

[18] C. Jingming, "Evaluation of vegetation indices and a modified simple ratio for boreal applications," Can. J. Remote Sens., vol. 22, no. 3, pp. 229-242, 1996.

[19] N. H. Broge and E. Leblanc, "Comparing prediction power and stability of broadband and hyperspectral vegetation indices for estimation of green leaf area index and canopy chlorophyll density," Remote Sens. Environ., vol. 76, no. 2, pp. 156-172, 2001.
[20] K. Oki et al., "Development of an environmentally advanced basin model in Asia," Crop Prod., chap. 2, pp. 17-48, 2013.

[21] P. S. Thenkabail, R. B. Smith, and E. De Pauw, "Hyperspectral vegetation indices and their relationships with agricultural crop characteristics," Remote Sens. Environ., vol. 71, no. 2, pp. 158-182, 2000.

[22] O. Mutanga and A. K. Skidmore, "Narrow band vegetation indices overcome the saturation problem in biomass estimation," Int. J. Remote Sens., vol. 25, no. 19, pp. 3999-4014, 2004.

[23] W. Chaoyang, N. Zheng, T. Quan, and H. Wenjiang, "Estimating chlorophyll content from hyperspectral vegetation indices: Modeling and validation," Agric. For. Meteorol., vol. 148, no. 8, pp. 1230-1241, 2008.

[24] H. Wenjiang, D. W. Lamb, N. Zheng, Z. Yongjiang, L. Liu, and J. Wang, "Identification of yellow rust in wheat using in-situ spectral reflectance measurements and airborne hyperspectral imaging," Precis. Agric., vol. 8, no. 4-5, pp. 187-197, 2007.

[25] H. Wenjiang, W. Jihua, W. Zhijie, Z. Jiang, L. Liangyun, and W. Jindi, "Inversion of foliar biochemical parameters at various physiological stages and grain quality indicators of winter wheat with canopy reflectance," Int. J. Remote Sens., vol. 25, no. 12, pp. 2409-2419, 2004.

[26] Z. Jingcheng et al., "Development, evaluation and application of a spectral knowledge base to detect yellow rust in winter wheat," Precis. Agric., vol. 12, no. 5, pp. 716-731, 2011.

[27] X. Qiaoyun et al., "Leaf area index estimation using vegetation indices derived from airborne hyperspectral images in winter wheat," IEEE J. Sel. Topics Appl. Earth Observ. Remote Sens., vol. 7, no. 8, pp. 3586-3594, 2014.

[28] S. Abraham and M. J. E. Golay, "Smoothing and differentiation of data by simplified least squares procedures," Anal. Chem., vol. 36, no. 8, pp. 1627-1639, 1964.

[29] P. J. Zarco-Tejada, J. Miller, A. Morales, A. Berjón, and J. Agüera, "Hyperspectral indices and model simulation for chlorophyll estimation in open-canopy tree crops," Remote Sens. Environ., vol. 90, no. 4, pp. 463-476, 2004.

[30] Y. Zhang, J. M. Chen, J. R. Miller, and T. L. Noland, "Leaf chlorophyll content retrieval from airborne hyperspectral remote sensing imagery," Remote Sens. Environ., vol. 112, no. 7, pp. 3234-3247, 2008.

[31] R. Darvishzadeh, A. Skidmore, M. Schlerf, and C. Atzberger, "Inversion of a radiative transfer model for estimating vegetation LAI and chlorophyll in a heterogeneous grassland," Remote Sens. Environ., vol. 112, no. 5, pp. 2592-2604, 2008.

[32] A. Verger, F. Baret, and F. Camacho, "Optimal modalities for radiative transfer-neural network estimation of canopy biophysical characteristics: Evaluation over an agricultural area with CHRIS/PROBA observations," Remote Sens. Environ., vol. 115, no. 2, pp. 415-426, 2011.

[33] M. Lüdeke, A. Janecek, and G. H. Kohlmaier, "Modelling the seasonal CO2 uptake by land vegetation using the global vegetation index," Tellus $B$, vol. 43, no. 2 , pp. $188-196,1991$.

[34] M. Marshall and P. Thenkabail, "Biomass modeling of four leading world crops using hyperspectral narrowbands in support of HyspIRI mission," Photogramm. Eng. Remote Sens., vol. 80, no. 8, pp. 757-772, 2014.

[35] P. Gong, R. Pu, G. S. Biging, and M. R. Larrieu, "Estimation of forest leaf area index using vegetation indices derived from Hyperion hyperspectral data," IEEE Trans. Geosci. Remote Sens., vol. 41, no. 6, pp. 1355-1362, 2003.

[36] P. Ruiliang and G. Peng, "Hyperspectral remote sensing of vegetation bioparameters," Advances in Environmental Remote Sensing. Boca Raton, FL, USA: CRC Press, 2011, pp. 101-142.

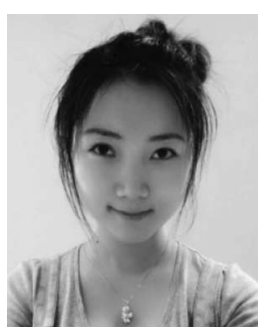

Qiaoyun Xie received the Master's degree in signal and information processing from Anhui University, Hefei, China, in 2014. Currently, she is pursuing the second year Ph.D. degree at the Key Laboratory of Digital Earth Science, Institute of Remote Sensing and Digital Earth, Chinese Academy of Sciences, Beijing, China, and the University of Chinese Academy of Sciences, Beijing, China.

Her research interests include quantitative remote sensing application in agriculture and development of software for digital image processing. 


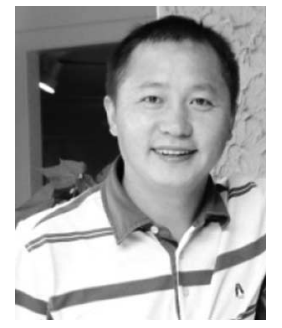

Wenjiang Huang received the Ph.D. degree in cartography and GIS from Beijing Normal University, Beijing, China, in 2005.

Currently, he is a Professor with the Key Laboratory of Digital Earth Science, Institute of Remote Sensing and Digital Earth, Chinese Academy of Sciences, Beijing, China. His research interests include quantitative remote sensing research and application in vegetation.

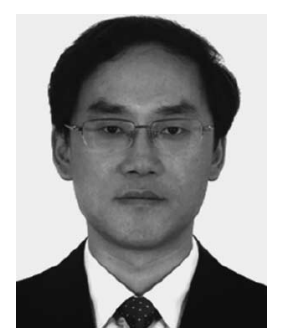

Bing Zhang (M'11-SM'12) received the B.S. degree in geography from Peking University, Shenzhen, China, the M.S. and Ph.D. degrees in remote sensing from the Institute of Remote Sensing Applications, Chinese Academy of Sciences (CAS), Beijing, China.

Currently, he is a Professor and the Deputy Director of the Institute of Remote Sensing and Digital Earth, CAS. His research interests include the development of physics-based models and image processing software for the use of hyperspectral remote sensing data in solving problems in geology, hydrology, ecology, and botany.

Dr. Zhang is the recipient of several Chinese National, Ministerial, and Provincial S\&T Progress Awards for his innovative research and research-based development projects undertaken by him.

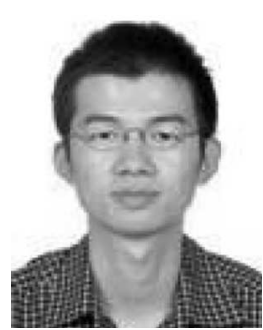

Pengfei Chen received the M.S. degree in grass science and the Ph.D. degree in land use and information technology from China Agricultural University, Beijing, China, in 2006 and 2009, respectively.

From July 2009, he works with the Institute of Geographic Sciences and Natural Resources Research, Chinese Academy of Sciences, Beijing, China, where he is currently an Assistant Researcher. His research interests include application of remote sensing and crop growth model technology in agricultural management.

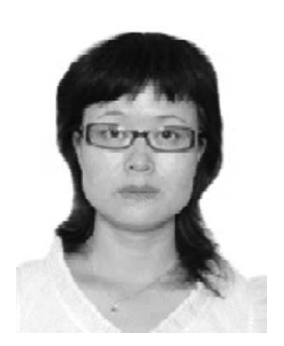

Xiaoyu Song received the Ph.D. degree in geographic information system and remote sensing from Beijing Normal University, Beijing, China, in 2009.

Currently, she is a Research Associate with Beijing Research Center for Information Technology in Agriculture, Beijing, China. Her research interests include remote sensing image process, crop growth monitoring, and precision agriculture application by remote sensing.

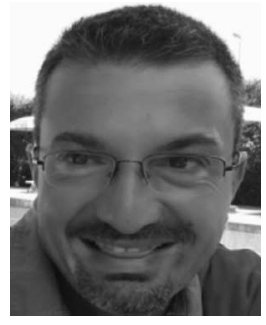

Simone Pascucci received the degree in environmental sciences from the University of La Tuscia, Viterbo, Italy, in 2002.

Since 2002, he pursued research activities on multi and hyperspectral remote sensing with the National Research Council of Italy (CNR), Rome, Italy. He has authored more than 50 articles in international journals and conference proceedings regarding applications of hyperspectral remote sensing from aircraft (MIVIS and CASI) and satellite (Hyperion, CHRIS) within the geological, urban, marine, forestry and for the detection and estimation of materials, soil properties, and pollutants.

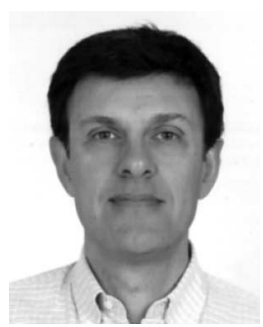

Stefano Pignatti was born in Verona, Italy, in 1965. $\mathrm{He}$ received the Laurea degree in geology from the University of Rome "La Sapienza," Rome, Italy, in 1988.

Since 1995, he has been a Researcher with the National Research Council of Italy and from 2001 as a Confirmed Researcher with the Institute of Methodologies for Environmental Analysis (CNR IMAA), Rome, Italy. Since 1990, he has been working on hyperspectral remote sensing both from airborne (VSWIR and TIR) and satellite platforms. He works on data calibration issues as well as for the exploitation of hyperspectral remote sensing in environmental applications.

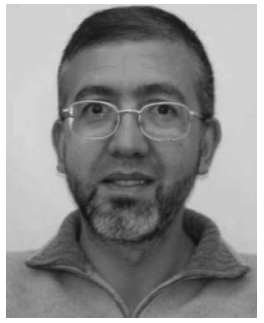

Giovanni Laneve (M'02) was born in Viggiano, Italy, in 1960. He received the Laurea degree in aeronautic engineering from the Università di Napoli, Naples, Italy, in 1985, and the Laurea degree in aerospace engineering from the Università di Roma "La Sapienza," Rome, Italy, in 1988.

He has authored more than 120 scientific papers. His research interests include aeronomy, satellite thermal control, mission design, new algorithms for the exploitation of satellite images, satellite remote sensing applications for fire management, applications of satellite data for the African regions, and studies on environmental and disaster monitoring.

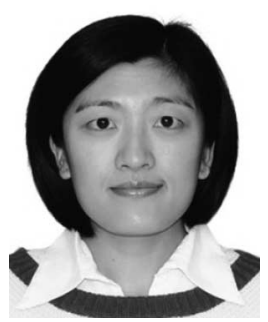

Yingying Dong received the B.S. degree in information and computation science from Shandong Normal University, Shandong, China, in 2006, the M.S. degree in mathematics of computation from Capital Normal University, Beijing, China, in 2009, and the Ph.D. degree in agricultural remote sensing and information technology from Zhejiang University, Zhejiang, China, in 2013.

Her research interests include research and application in vegetation remote sensing. 